(2)

\section{OPEN ACCESS}

'Otorhinolaryngolgy, CHUV, Lausanne, Vaud, Switzerland ${ }^{2}$ Otorhinolarygology, Hôpitaux Universitaires de Genève, Genève, Switzerland

Correspondence to Dr Charles-Arnaud Serex: charles-arnaud.serex@chuv.ch

Accepted 30 December 2020

Check for updates

(c) BMJ Publishing Group Limited 2021. Re-use permitted under CC BY-NC. No commercial re-use. See rights and permissions. Published by BMJ.

To cite: Serex C-A Dulguerov N. BMJ Case Rep 2021:14:e237360 doi:10.1136/bcr-2020237360

\title{
Rapidly progressive stridor in a case of GIST
}

\author{
Charles-Arnaud Serex, ${ }^{1}$ Nicolas Dulguerov ${ }^{2}$
}

\section{SUMMARY}

We report the case of an 84-year-old male patient suffering from a gastrointestinal stromal tumour (GIST) of the rectum who was referred to our ENT (Ear-NoseThroat) clinic for a rapidly progressive stridor, aphagia and dysphonia. The clinical examination revealed a mass arising from the posterior wall of the pharynx, which obstructed the laryngeal inlet and thus the airway. A metastasis of the GIST was suspected. After completing the investigation with radiological imaging, the patient underwent surgery, which consisted of a tracheostomy to secure the airway and a biopsy of the mass. The pathological examination confirmed the suspected diagnosis of a GIST vertebral metastasis.

\section{BACKGROUND}

This case highlights a rare presentation and complication of a pararectal gastrointestinal stromal tumour (GIST) vertebral metastasis causing a pharyngeal mass compromising the upper aerodigestive tract, requiring an urgent securing of the airway. We describe the perioperative management of a posterior pharyngeal wall mass obstructing the airway.

\section{CASE PRESENTATION}

We report the case of an 84-year-old man suffering from a pararectal metastatic GIST, diagnosed 22 months ago in January 2018. At the time of the diagnosis, the disease was already metastatic to the lymph nodes (mesorectal and iliac lymph nodes) and to the bone (iliac bone). The patient was otherwise known for treated hypertension and hypercholesterolaemia and had unremarkable history. An immunotherapy by tyrosine kinase inhibitors (imatinib, GLIVEC) was conducted for 6 months. The occurrence of a Stevens-Johnson syndrome led to the interruption of the immunotherapy. The multidisciplinary team agreed on a surgical procedure. A resection of the tumour was performed in August 2019. The initial pathological stage was an ypT4 N0 (0/22) MX L0 V0 Pn0 RX. There were 10 mitoses/50 high power field (HPF) indicating a tumour with high risk of metastasis. ${ }^{1}$ There were no mutation analysis performed on the pathological sample nor precisions on the immunohistochemistry used. A stereotaxic radiotherapy on the three metastatic bone lesions was performed.

On November 2019, he was referred to our ENT clinic for rapidly progressive stridor, aphagia and dysphonia. A nasofibroscopic examination revealed a large, elastic, non-pulsatile mass $(\mathrm{ca} .3 \mathrm{~cm}$ ) with a normal-looking overlying mucosa, arising from the posterior wall of the lower oropharynx in contact with the epiglottis (figure 1). It obstructed the laryngeal inlet. The larynx was otherwise unremarkable and functional.

The initial care consisted in placing a nasogastric feeding tube. Complimentary imagery by CT scan and MRI was scheduled. They confirmed the suspected diagnosis of a GIST vertebral metastasis.

The safety of the airway was clearly compromised. A tracheostomy associated with biopsies of the lesion under general anaesthesia was organised.

The intervention was carefully planned in the presence of the ENT and anaesthesiology team in case the patient was impossible to ventilate and to intubate and in the event that the tracheostomy had to be made under local anaesthesia. Because the lesion was on the posterior pharyngeal wall and because the larynx was visible on the fibreoptic examination, we decided to perform a classic orotracheal intubation instead of an awake fibreoptic intubation.

After the induction of the sedative agent, the larynx was easily exposable with the Macintosh laryngoscope blade (figure 1). The patient was intubated, and a surgical tracheostomy was performed (Björk technique and Shiley 6DFEN cannula) as well as biopsies of the lesion.

\section{INVESTIGATIONS}

The initial evaluation was the clinical examination at the ENT clinic. The patient had a 'hot potato' voice and a stridor persistent with change in body position. The endobuccal examination revealed a round, elastic mass of the posterior wall of the oropharynx without mucosal anomaly. The cervical palpation was normal. The videoendoscopy allowed us to bypass the mass and visualise the larynx, which was unremarkable.

Prior to surgical biopsies, the investigations were completed with radiological examinations (CT scan and MRI). The cervicofacial CT showed an infiltrative lesion of the vertebral and prevertebral space at the level of $\mathrm{C} 3$, with partial destruction of the $\mathrm{C} 2$ and $\mathrm{C} 3$ vertebral bodies, causing a mass effect on the oropharynx and hypopharynx. The

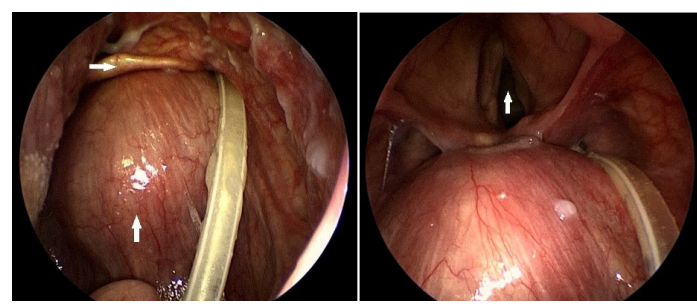

Figure 1 Left: endoscopic view showing posteriorly the pharyngeal mass $(\uparrow)$ in contact with the thin epiglottis $(\rightarrow)$ visible anteriorly. Right: exposition of the larynx $(\uparrow)$ with a Macintosh laryngoscope blade. 

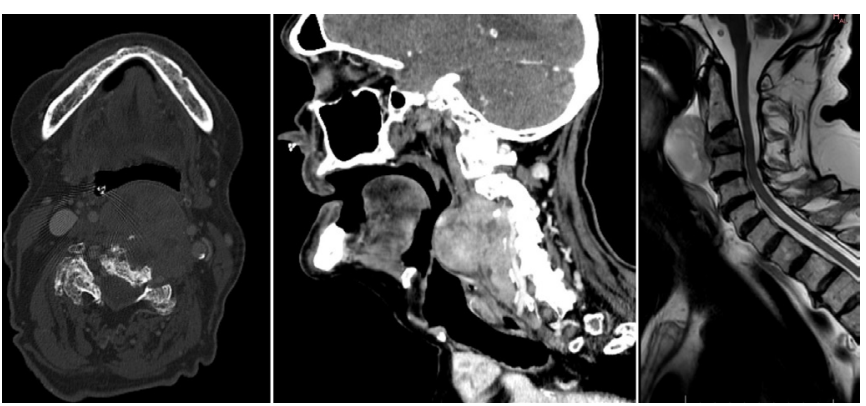

Figure 2 Left: native axial CT showing the prevertebral mass with C3 vertebral body erosion. Middle: soft tissue sagittal CT showing the protrusion of the posterior mass against the epiglottis. Right: T2 sagittal MRI showing the protrusion of the lesion in the pharynx.

cervicofacial MRI revealed a $7.2 \times 5.2 \times 4.8 \mathrm{~cm}$ mass compatible with a metastatic vertebral lesion of the known GIST (figure 2).

\section{DIFFERENTIAL DIAGNOSIS}

The differential diagnosis included a pharyngeal squamous cell carcinoma, a metastatic lesion, a vascular malformation (aneurysm), an infectious disease (spondylodiscitis), an inflammatory lesion or a vertebral osteophyte.

\section{TREATMENT}

For the safety of the airway and for the purpose of a diagnosis, a tracheostomy under general anaesthesia associated with biopsies of the pharyngeal lesion was performed. There were no complications. The sites in which the biopsies were taken healed unremarkably as well as the tracheostomy site.

\section{OUTCOME AND FOLLOW-UP}

The pathological analysis was consistent with a vertebral bone metastasis of the known GIST. Fusiform cells with eosinophilic cytoplasm and fasciculate architecture (figure 3) were identified, which are characteristic of GIST. The histological image was similar to the primary GIST pathological analysis.

In conclusion, the diagnosis was a metastatic vertebral lesion of the known GIST.

The oncologist was in charge of the patient follow-up. A new attempt of tyrosine kinase inhibitor treatment was planned with a palliative perspective. Unfortunately, the patient passed away 2 months after our initial consultation.

\section{DISCUSSION}

The GIST is the most frequent mesenchymal tumour of the gastrointestinal (GI) tract. It has a slight male predominance and usually occurs around the age of 60 . The most common presentation symptom is GI bleeding. The prognosis depends on the tumour size and on the mitotic activity. The risk of metastases

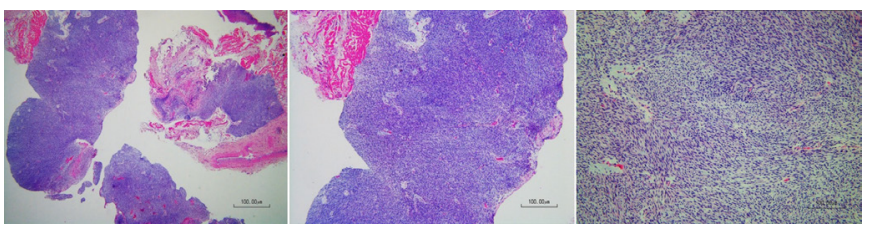

Figure 3 Microscopic analysis of the biopsy showing fusiform cells with eosinophilic cytoplasm (coloured in purple) and fasciculate architecture typical of a gastrointestinal stromal tumour. is $86 \%$ if the tumour is larger than $10 \mathrm{~cm}$ and/or contains five mitoses $/ 50 \mathrm{HPF}^{1}$ as seen in our patient with a tumour of $19 \mathrm{~cm}$ and with 10 mitosis/50 HPF.

The most common site of presentation is the stomach $(39 \%$ $60 \%$ ), followed by the small bowel (35\%), and more rarely, it can be found in other locations $(<5 \%$ in the rectum, colon and oesophagus). ${ }^{2}$

GISTs usually metastasise to the liver (53\%-71\%) but also to the peritoneum. Bone metastases are rare $(4 \%)^{3}$ and are generally associated with aggressive GISTs originating from other locations than the stomach or that are already metastatic to the liver. $^{2}$

The treatment of small tumours consists in surgical excision followed by immunotherapy with tyrosine kinase inhibitors (imatinib). For larger and unresectable tumours or metastatic tumours, imatinib is considered the first-line treatment.

A large number of GISTs will be recurrent or will present metastasis in the follow-up (30\%-50\%). ${ }^{4}$

At our knowledge, there is no known publication of metastatic GIST to the cervical vertebral bodies obstructing the upper aerodigestive tract.

A review of metastatic vertebral lesion of other tumours that compromised the airways was conducted, and no publications on this subject were identified.

Our case depicts an unusual presentation of a metastatic GIST involving the upper aerodigestive tract with a sudden obstruction of the airways secondary to a rare bone metastasis of this tumour. We aimed to present the clinical steps in the management of a patient with an upper aerodigestive tract obstruction.

\section{Patient's perspective}

We were really anxious about the breathing disorder of my father. When the pharyngeal lesion was discovered, we wondered what it could be. When the ENT explained to us that it was probably related to his cancer and that my father would need a tracheostomy, I was in shock.

After the surgery, I understood why it was so important to proceed with this intervention. My father was able to breath normally again and could even speak.

I was relieved to see him more comfortable and less tired. He was not obligated to sleep in a sitting position anymore. We were able to spend some quality time again together without him struggling to breathe.

Even if the result of the biopsies showed that it was a metastasis of his cancer, this procedure made his quality of life better for his last months. Unfortunately, he died of his cancer.

\section{Learning points}

- Cervical bone metastasis is a rare, potentially life-threatening condition obstructing the upper airways.

- An experienced surgical and anaesthesiology team must manage airway obstruction.

- A posterior pharyngeal mass in an oncological patient should trigger a search on a possible vertebral bone metastasis.

- Preoperative imaging is mandatory before safely performing biopsies of the posterior pharyngeal wall.

- Bone metastases from gastrointestinal stromal tumours are rare but should be considered nonetheless, especially in aggressive primary tumours. 
It consists in securing the airway and establishing a diagnosis for adequate therapeutical care. A multidisciplinary management involving the ENT, anaesthesiology, oncology and pathology team was required.

Contributors C-AS saw the patient at the emergency, performed the clinical examination and after that performed the tracheostomy to the patient under the supervision of ND. C-AS signed the consent with the patient with the purpose of writing a case report. The case report was written by C-AS and reviewed by ND before submitting it to the BMJ. We decided to write a case report due to the rarity of the clinical presentation of the disease in the airways.

Funding The authors have not declared a specific grant for this research from any funding agency in the public, commercial or not-for-profit sectors.

Competing interests None declared.

Patient consent for publication Obtained.

Provenance and peer review Not commissioned; externally peer reviewed.
Open access This is an open access article distributed in accordance with the Creative Commons Attribution Non Commercial (CC BY-NC 4.0) license, which permits others to distribute, remix, adapt, build upon this work non-commercially, and license their derivative works on different terms, provided the original work is properly cited and the use is non-commercial. See: http://creativecommons.org/ licenses/by-nc/4.0/.

\section{REFERENCES}

1 Miettinen M, Sobin LH, Lasota J. Gastrointestinal stromal tumors of the stomach: a clinicopathologic, immunohistochemical, and molecular genetic study of 1765 cases with long-term follow-up. Am J Surg Pathol 2005;29:52-68.

2 Nakajima T, Sugiyama T, Baba H, et al. Bone metastasis in gastrointestinal stromal tumors preferentially occurs in patients with original tumors in sites other than the stomach. Int J Clin Exp Pathol 2015;8:5955-9.

3 DeMatteo RP, Lewis JJ, Leung D, et al. Two hundred gastrointestinal stromal tumors: recurrence patterns and prognostic factors for survival. Ann Surg 2000;231:51-8.

4 Guo Y, Liu J, Wang F, et al. The role of surgical resection following tyrosine kinase inhibitors treatment in patients with advanced gastrointestinal stromal tumors: a systematic review and meta-analysis. J Cancer 2019;10:5785-92.

Copyright 2021 BMJ Publishing Group. All rights reserved. For permission to reuse any of this content visit https://www.bmj.com/company/products-services/rights-and-licensing/permissions/

BMJ Case Report Fellows may re-use this article for personal use and teaching without any further permission.

Become a Fellow of BMJ Case Reports today and you can:

- Submit as many cases as you like

- Enjoy fast sympathetic peer review and rapid publication of accepted articles

- Access all the published articles

- Re-use any of the published material for personal use and teaching without further permission

Customer Service

If you have any further queries about your subscription, please contact our customer services team on +44 (0) 2071111105 or via email at support@bmj.com.

Visit casereports.bmj.com for more articles like this and to become a Fellow 